\title{
Dietary Patterns and Breast Cancer Risk in the Shanghai Breast Cancer Study
}

\author{
Xiaohui Cui,1 Qi Dai,2,3 Marilyn Tseng,4 Xiao-Ou Shu,2,3 Yu-Tang Gao,5 and Wei Zheng, \\ 1. Department of Epidemiology, Harvard School of Public Health, Boston, Massachusetts; \\ 2. Vanderbilt Epidemiology Center, Department of Medicine, School of Medicine, and \\ 3. Vanderbilt-Ingram Cancer Center, Vanderbilt University, Nashville, Tennessee; \\ 4. Division of Population Science, Fox Chase Cancer Center, Philadelphia, Pennsylvania; and \\ 5. Department of Epidemiology, Shanghai Cancer Institute, Shanghai, People's Republic of China
}

\begin{abstract}
The association of breast cancer with dietary patterns such as a western diet has not been studied in Asian women. We examined this among Shanghai Breast Cancer Study participants. Cases were of ages 25 to 64 years, diagnosed 08/1996-03/ 1998, and identified through a rapid case ascertainment system supplemented by the Shanghai Cancer Registry. Controls, selected from the general population of urban Shanghai, were frequency matched to cases by 5-year age group. Participants provided information on diet, lifestyle, and reproductive factors. In principal component analysis among 1,556 controls, two patterns emerged: a "vegetable-soy" pattern (tofu, cauliflower, beans, bean sprouts, green leafy vegetables) and a "meat-sweet" pattern (shrimp, chicken, beef, pork, candy, desserts). In adjusted unconditional logistic regression analyses including 1,446 cases and 1,549 controls with complete covariate data, risk was not associated with the vegetable-soy pattern. It was associated with the meat-sweet pattern (4th versus 1st quartile: odds ratio, 1.3; 95\% confidence interval, 1.0-1.7; Ptrend $=0.03$ ), but only in postmenopausal women, specifically among those with estrogen receptor-positive tumors (4th versus 1st quartile: odds ratio, 1.9; 95\% confidence interval, 1.1-3.3; Ptrend 0.03). Our findings indicate that a western diet increases breast cancer risk in postmenopausal Chinese women. They also suggest the value of quantifying aggregate risk for common combinations of foods.
\end{abstract}

\section{Introduction}

Ecologic studies implicate a western diet, generally characterized by high intake of beef or pork, white flour bread, and potatoes (1), in breast cancer etiology (2). However, few studies have tested this hypothesis by quantifying intake of such a dietary pattern among individuals. Studies on dietary patterns and breast cancer risk conducted among U.S. (3-5) or European (6-8) populations have had mixed findings. The issue is of particular relevance to women in Asia, for whom breast cancer rates are traditionally low, but increasing steadily in recent years (9). The transition in breast cancer risk has been attributed to environmental factors, possibly the incorporation of western dietary pattern foods into traditional dietary habits as a part of broader, societal socioeconomic changes (10), but the association of dietary patterns with breast cancer risk has not previously been studied in Asian women. By quantifying the aggregate risk associated with recognizable combinations of foods, a dietary pattern approach provides a useful complement to findings based on single nutrients or single food groups. 
The objectives of our analyses were to identify and measure intake of dietary patterns in Chinese women using principal component analysis and to examine associations between dietary patterns and breast cancer risk among participants in the Shanghai Breast Cancer Study. We were specifically interested in confirming the existence of a western dietary pattern in a Chinese sample and in assessing whether such a pattern increases breast cancer risk.

\section{Materials and Methods}

The Shanghai Breast Cancer Study was a population-based case control study conducted among Chinese women in Shanghai. Eligible cases included all women 25 to 64 years of age, who were newly diagnosed with breast cancer from August 1996 to March 1998. A rapid case ascertainment system, supplemented by the population-based Shanghai Tumor Registry, has virtually complete ascertainment of all incident cancer cases diagnosed among residents in urban Shanghai (11). Of 1,602 eligible breast cancer cases identified during the study period, in-person interviews were completed for 1,459 (91.1\%). Reasons for nonparticipation were refusal $(\mathrm{N}=109 ; 6.8 \%)$, death before interview $(\mathrm{N}=17$; $1.1 \%)$, and inability to locate $(\mathrm{N}=17 ; 1.1 \%)$. Cancer diagnoses for all patients were reviewed and confirmed by two senior pathologists. Controls were selected from the Shanghai Resident Registry of permanent residents in urban Shanghai and frequency matched to cases by 5-year age groups. In-person interviews were completed for 1,556 of the 1,724 (90.3\%) eligible controls. Reasons for nonparticipation were refusal $(\mathrm{N}=166$; 9.6\%) and death $(\mathrm{N}=2 ; 0.1 \%)$.

All study participants were interviewed using a structured questionnaire that included 76 food items that cover $>85 \%$ of foods consumed in Shanghai. A validation of the dietary questionnaire was conducted in a study of f200 Shanghai women with 24 days (twice a month) of 24-h dietary recalls (12). For the dietary interview, each participant was first asked how frequently she consumed a specific food or group of foods (per day, week, month, year, or never), followed by a question on how many liangs (1 liang $=50 \mathrm{~g}$ ) she usually ate per unit of time in the majority of the time over the previous 5-year period, ignoring any recent changes. Other interview information included family and health history, reproductive factors, physical activity, and smoking. All participants were measured for their current weight and circumferences of the waist and hip.

Patterns of food intake were identified by principal component analysis $(13,14)$ using frequency responses to the dietary questionnaire among controls only. ${ }^{6}$ Individuals were randomly placed into one of two equally sized groups, or split samples, to confirm reproducibility of the principal components identified. For the first split sample, a matrix of correlations among grams per day of consumption for the questionnaire food items was constructed and entered in the analysis. Extraction of principal components was followed by orthogonal rotation of retained components to allow for interpretability $(13,14)$. The number of components to retain for rotation was based on examination of scree plots and interpretability of the components (14); although another common strategy is to rotate all factors with eigenvalues $>1.0$, this method has been shown to overestimate the number of components (14). The analysis was repeated in the second split sample to confirm reproducibility of results. Cronbach's coefficient a (15) was used to evaluate internal consistency for each component retained. In psychometric research, a coefficient $\alpha \geq 0.70$ 
generally indicates acceptable reliability (16), although in previous research, dietary pattern scales with coefficient a as low as 0.5 to 0.6 were predictive of disease (17).

A component score was calculated for each dietary pattern for each individual in the sample (cases and controls) to represent the individual's level of intake for the pattern. The score for each pattern was computed as a linear composite of the foods with meaningful loadings $(\geq|0.20|)$ for only that pattern. Scores were calculated by taking the unweighted sum of standardized frequencies of intake for each food associated with the pattern.

Student's t test was used for the comparison of continuous variables between cases and controls, and the $\mathrm{m}^{2}$ test was used for categorical variables. We used unconditional logistic regression to estimate odds ratios (OR) and 95\% confidence intervals (95\% CI) for quartiles of component scores. All ORs were adjusted for age (continuous, years) and energy intake (continuous, kilocalories). Final models were additionally adjusted for family history of breast cancer (yes, no), personal history of fibroadenoma (yes, no), age at menarche $(\leq 12,13,14,15,16, \geq 17$ years $)$, any live births and age at first live birth $(<20,20$ $24,25-29,30-34, \geq 35$ years, nulliparous), menopausal status and age at menopause (premenopausal, age at menopause $<45,45-49,50-54, \geq 55$ years), regular physical activity during last 10 years (yes, no), waist-to-hip ratio (WHR; continuous), body mass index (BMI; continuous), and level of education (no formal education, elementary, middle and high school, college and higher). P values for linear trend were obtained for each dietary pattern by including an ordinal variable representing the scaled median value for each quartile in the final multivariate model.

Additional models considered the possibility of effect modification by menopausal status and by obesity, as indicated by BMI and WHR, as well as possible differences in effect by estrogen receptor and progesterone receptor status. In these analyses, we dichotomized BMI at $25 \mathrm{~kg} / \mathrm{m}^{2}$ as the cutoff point for non-overweight versus overweight, and WHR at 0.835 (the lower bound of the 4th quartile). Interaction terms were calculated as the products of the stratified factors (dichotomous) and the scale for each quartile of the dietary patterns.

The analyses were conducted using SAS Statistical Software, version 9 (SAS Institute) ${ }^{7}$; statistical tests were two sided. For all analyses, $\mathrm{P}<0.05$ was considered statistically significant.

\section{Results}

Descriptive characteristics of the study sample by case-control status are shown in Table 1. Compared with controls, cases were slightly older, had higher educational level, earlier age at menarche, later menopausal age, later age at first live birth, higher BMI and WHR, and less likely to be physically active during the last 10 years.

In principal components analyses, two dietary patterns emerged consistently across the split samples (Table 2). The first, which we describe as a "vegetable-soy" pattern, was characterized by high factor loadings for a variety of different vegetables, soy-based products, and freshwater fish. The second, which we describe as a "meat-sweet" pattern, was characterized by high factor loadings for various meats, primarily pork but also poultry, organ meats, beef and lamb, and shrimp, saltwater fish, and shellfish, as well as candy, dessert, bread, and milk. 
We described the distributions of selected sociodemographic and health-related characteristics across pattern quartiles (Table 3). Women with higher consumption of the vegetable-soy pattern were more likely to be physically active. Women with higher consumption of the meat-sweet pattern were younger, better educated, had later menopausal age, and were less likely to have had their first live birth before age 25 years. The vegetable-soy pattern was strongly correlated with intake of fiber, vitamins $\mathrm{C}$ and $\mathrm{E}$, soy protein, legume, and vegetables, whereas the meat-sweet pattern was strongly correlated with intake of total and saturated fats and red meat.

In unconditional logistic regression models, whereas the vegetable-soy pattern was not associated with breast cancer risk in any models whether unstratified or stratified, risk was increased in the highest quartile of the meat-sweet pattern (4th versus 1st quartile: OR, 1.3; 95\% CI, 1.0-1.7; $\mathrm{P}_{\text {trend }}=0.03$; Table 4). This association was only true for postmenopausal women, specifically among those with estrogen receptor- positive tumors (4th versus 1st quartile: OR, 1.9; 95\% CI, 1.13.3; $\mathrm{P}_{\text {trend }}=0.03$; Table 5).

To evaluate the possibility of effect modification by obesity, we further stratified on BMI $(\geq 25,<25)$ and WHR $(\geq 0.835,<0.835)$. While none of the interaction terms was significant, we found suggestive evidence for effect modification by BMI. Among overweight postmenopausal women, the OR for estrogen receptor-positive tumors was 2.3 (4th versus 1st quartile; 95\% CI, 1.0-5.4; $\mathrm{P}_{\text {trend }}=0.02$ ) whereas among women with BMI $<25$, the association was weaker with no linear trend (Table 6). However, when we included estrogen receptor-negative tumors in the analyses, there was no difference between two groups (results not shown). We saw no evidence of effect modification by WHR, but in additional analyses in more specific WHR categories, risk was especially elevated among women in the third quartile for WHR, with WHR z0.80 and $<0.835$ (4th versus 1st quartile: $0 R, 4.7 ; 95 \%$ CI, 1.1-19.2; $P_{\text {trend }}=0.02$ ).

\section{Discussion}

In this population-based case-control study, we identified two dietary patterns: vegetablesoy and meat-sweet. Our results showed no overall association of breast cancer risk with the vegetable-soy pattern but a positive association with the meat-sweet pattern. In stratified analyses, the meat-sweet pattern was significantly associated with increased risk of estrogen receptor-positive breast cancer among postmenopausal women, specifically in the subset of women with BMI $>25$.

The patterns identified in this sample somewhat resemble two primary patterns consistently identified across U.S. $(1,18)$ and European (19) populations: a "prudent" or "healthy" pattern characterized by intake of vegetables, and a second, "western" pattern characterized by intake of red meats and starches. Two similar, distinct dietary patterns emerged in a study conducted among Singaporean Chinese: a "vegetablefruit-soy" pattern and a "meat-dim sum" pattern that primarily included chicken, pork, fish, rice, and noodle dishes (20). The meat-based pattern is associated with less education in western populations (1) but with greater education in this sample and in the Singaporean Chinese sample (20), reflecting the different social contexts in which such a pattern can develop.

Results from previous studies on dietary patterns and risk of breast cancer have been inconsistent $(3-8,21)$ but generally found little evidence for an association of either the prudent or western pattern with breast cancer risk, with the exception of a case-control study conducted in Uruguay (21). In the Swedish Mammography Screening Cohort, breast 
cancer risk was moderately increased only for women in the highest category of the "drinker" dietary pattern, characterized chiefly by intake of wine, liquor, and beer (6). In a prospective study on postmenopausal breast cancer from the Nurses' Health Study, the prudent pattern was inversely associated with estrogen receptor-negative cancer, and the western pattern was associated with breast cancer risk only among smokers (3). Breast cancer risk was inversely associated with the "salad vegetables" pattern, characterized by intake of raw vegetables and olive oil, particularly among women with BMI $<25 \mathrm{~kg} / \mathrm{m}^{2}$ in the ORDET cohort in Italy (7); with a "pork, processed meat, potatoes" pattern in the Netherlands cohort in the DIETSCAN project (8); and with a traditional southern dietary pattern in the Breast Cancer Detection Demonstration Project in the United States (4).

In our study, intake of a vegetable-soy dietary pattern was not protective. This finding is consistent with that found in our studies that intakes of total vegetables and fruits were not associated with risk of breast cancer (22) although some specific nutrients and fruits and vegetables such as soy foods (23), vitamin E (22), and folate (24) may be related to a reduced risk. Several explanations for the null association for the vegetable-soy pattern are possible. First, the protective effect of individual foods could be diluted or countered by other foods in this pattern. Freshwater fish, for example, was positively associated with breast cancer in this sample in previous analyses (25). When we recalculated the pattern score excluding freshwater fish, however, the association between vegetable-soy pattern and breast cancer risk remained null (results not shown). Second, vegetables are generally cooked before eating in Chinese cuisine, whereas food preparation and cooking process may substantially affect nutrient components, such as vitamin $\mathrm{C}$ and polyphenols, in foods. Therefore, raw and cooked vegetables may have different effects on risk of breast cancer. In the ORDET cohort, the prudent pattern, characterized primarily by cooked vegetables, pulses, and fish, was not correlated with breast cancer, but the salad vegetables pattern was (7). Third, there is a substantial interindividual variation in bioavailable nutrients, such as isoflavonoids and other polyphenols, after ingestion of soy and other related foods $(26,27)$. A final possibility is that nondifferential measurement error from the food frequency questionnaire may have biased the results toward the null.

We are the first to find evidence for an increased risk of breast cancer for a westernstyle dietary pattern in an Asian population. Our results are consistent with previous analyses in the same sample that found that red meat, especially well-done red meat, increased risk in premenopausal and postmenopausal women. Our findings, however, indicate that red meat intake in Shanghai occurs in a recognizably western-influenced dietary pattern now emerging in Asian populations (20). Previous studies on a western pattern in relation to breast cancer were conducted among western populations, which may have less variability in intake of such a pattern.

The significant association for our meat-sweet pattern was true only for estrogen receptor -positive tumors among postmenopausal women. This is analogous to the observation that obesity is correlated with higher risk of postmenopausal but not premenopausal breast cancer (28-31), and it suggests the possibility that the meat-sweet pattern increased risk by increasing obesity. After menopause, excess weight is associated with increased aromatization of androgens to estrogens and decreased levels of sex hormone binding globulin, thereby increasing bioavailable estrogen levels $(29,31-33)$. In our analyses, however, adjusting for BMI did not attenuate associations for the meat-sweet 
pattern (results not shown), suggesting that BMI was not in fact a mediator. We did, in contrast, find some evidence that BMI modified the effect of the meat-sweet pattern on estrogen receptor-positive tumors in postmenopausal women, consistent with previous findings about red meat intake in the same sample (25). Thus, obesity may interact with other factors in a meat-sweet pattern that stimulate the transformation from normal breast cells to tumor cells.

We observed effect modification by WHR only when we broke WHR down into smaller categories. The strongest association then appeared among the third but not the highest quartile. Obesity, especially central obesity, has been associated with insulin resistance (34) and higher levels of free insulin-like growth factor I (35), and any effect modification by WHR may be due to insulin resistance and hyperinsulinemia. Why we would observe the largest effect in the third rather than in the highest quartile, however, is unclear, and the small sample size after stratification may have led to some imprecision in estimates.

Limitations of the study include the possibility of error in measuring dietary intake and of recall bias due to its case-control design. However, through a rapid case-reporting system, we were able to complete an in-person interview for nearly half of the cases before they received any cancer treatment. Using principal component analysis to quantify dietary patterns may also involve some measurement error, but reasonably high $(>0.60)$ coefficient a for the patterns indicates good internal reproducibility for each pattern.

In summary, our study found the evidence that meat-sweet dietary pattern increased the risk of estrogen receptor-positive positive breast cancer among postmenopausal women with high BMI. Our findings suggest that for postmenopausal women, low consumption of a western dietary pattern plus successful weight control may protect against breast cancer in a traditionally low-risk Asian population that is poised to more broadly adopt foods characteristic of western societies.

\section{References}

1. Tseng M, DeVellis RF. Fundamental dietary patterns and their correlates among US whites. J Am Diet Assoc 2001;101:929 - 32.

2. Rose DP, Boyar AP, Wynder EL. International comparisons of mortality rates for cancer of the breast, ovary, prostate, and colon, and per capita food consumption. Cancer 1986;58:2363 - 71 .

3. Fung TT, Hu FB, Holmes MD, et al. Dietary patterns and the risk of postmenopausal breast cancer. Int J Cancer 2005;116:116 - 21.

4. Velie EM, Schairer C, Flood A, He JP, Khattree R, Schatzkin A. Empirically derived dietary patterns and risk of postmenopausal breast cancer in a large prospective cohort study. Am J Clin Nutr 2005;82:1308 - 19.

5. Adebamowo CA, Hu FB, Cho E, Spiegelman D, Holmes MD, Willett WC. Dietary patterns and the risk of breast cancer. Ann Epidemiol 2005;15: 789 - 95. 
6. Terry P, Suzuki R, Hu FB, Wolk A. A prospective study of major dietary patterns and the risk of breast cancer. Cancer Epidemiol Biomarkers Prev 2001;10:1281 - 5.

7. Sieri S, Krogh V, Pala V, et al. Dietary patterns and risk of breast cancer in the ORDET cohort. Cancer Epidemiol Biomarkers Prev 2004;13:567 - 72.

8. Mannisto S, Dixon LB, Balder HF, et al. Dietary patterns and breast cancer risk: results from three cohort studies in the DIETSCAN project. Cancer Causes Control 2005;16:725 33.

9. Yang L, Parkin DM, Li L, Chen Y. Time trends in cancer mortality in China: 1987 - 1999. Int J Cancer 2003;106:771 - 83.

10. Kolonel LN, Hankin JH, Nomura AM. Multiethnic studies of diet, nutrition, and cancer in Hawaii. Princess Takamatsu Symp 1985;16:29 - 40.

11. Cancer incidence in five continents. Volume VII. IARC Sci Publ 1997;(143):i - xxxiv, 1 1240.

12. Shu XO, Yang G, Jin F, et al, Validity and reproducibility of the food frequency questionnaire used in the Shanghai Women's Health Study. Eur J Clin Nutr 2004;58:17 - 23.

13. Kleinbaum D, Kupper LL, Muller KE. Applied regression analysis and other multivariable methods. Belmont (CA): Duxbury Press; 1988.

14. Kline P. An easy guide to factor analysis. New York: Routledge; 1994.

15. Cronbach LJ, Warrington WG. Coefficient a and the internal structure of tests. Psychometrika 1951;16:297 - 334.

16. Nunnally J. Psychometric theory. New York: McGraw-Hill; 1978.

17. Tseng M, DeVellis RF, Maurer KR, et al. Food intake patterns and gallbladder disease in Mexican Americans. Public Health Nutr 2000;3:233 - 43.

18. Hu FB, Rimm E, Smith-Warner SA, et al. Reproducibility and validity of dietary patterns assessed with a food-frequency questionnaire. Am J Clin Nutr 1999;69:243 - 9.

19. Balder HF, Virtanen M, Brants HA, et al. Common and country-specific dietary patterns in four European cohort studies. J Nutr 2003;133:4246 - 51.

20. Butler LM, Koh WP, Lee HP, Tseng M, Yu MC, London SJ. Prospective study of dietary patterns and persistent cough with phlegm among Chinese Singaporeans. Am J Respir Crit Care Med 2006;173:264 - 70. 
21. Ronco AL, De Stefani E, Boffetta P, Deneo-Pellegrini H, Acosta G, Mendilaharsu M. Food patterns and risk of breast cancer: a factor analysis study in Uruguay. Int J Cancer 2006;119:1672 - 8 .

22. Malin AS, Qi D, Shu XO, et al. Intake of fruits, vegetables and selected micronutrients inrelationtothe riskofbreastcancer.Int J Cancer 2003;105:413 -8.

23. Dai Q, Shu XO, Jin F, et al. Population-based case-control study of soyfood intake and breast cancer risk in Shanghai. Br J Cancer 2001;85:372 - 8.

24. Shrubsole MJ, Jin F, Dai Q, et al. Dietary folate intake and breast cancer risk: results from the Shanghai Breast Cancer Study. Cancer Res 2001;61:7136 - 41.

25. Dai Q, Shu XO, Jin F, Gao YT, Ruan ZX, Zheng W. Consumption of animal foods, cooking methods, and risk of breast cancer. Cancer Epidemiol Biomarkers Prev 2002;11:801 - 8.

26. Franke AA, Custer LJ. High-performance liquid chromatographic assay of isoflavonoids and coumestrol from human urine. J Chromatogr B Biomed Appl 1994;662:47 - 60.

27. Rowland IR, Wiseman H, Sanders TA, Adlercreutz H, Bowey EA. Interindividual variation in metabolism of soy isoflavones and lignans: influence of habitual diet on equol production by the gut microflora. Nutr Cancer 2000;36:27 - 32 .

28. Sweeney C, Blair CK, Anderson KE, Lazovich D, Folsom AR. Risk factors for breast cancer in elderly women. Am J Epidemiol 2004;160:868 - 75.

29. Althuis MD, Fergenbaum JH, Garcia-Closas M, Brinton LA, Madigan MP, Sherman ME. Etiology of hormone receptor-defined breast cancer: a systematic review of the literature. Cancer Epidemiol Biomarkers Prev 2004;13:1558 - 68.

30. Carmichael AR, Bates T. Obesity and breast cancer: a review of the literature. Breast $2004 ; 13: 85-92$.

31. Key TJ, Appleby PN, Reeves GK, et al. Body mass index, serum sex hormones, and breast cancer risk in postmenopausal women. J Natl Cancer Inst 2003;95:1218 - 26.

32. Hankinson SE, Willett WC, Manson JE, et al. Alcohol, height, and adiposity in relation to estrogen and prolactin levels in postmenopausal women. J Natl Cancer Inst 1995;87:1297 302.

33. Siiteri P. Adipose tissue as a source of hormones. Am J Clin Nutr 1987;45: 277 - 82.

34. Borugian MJ, Sheps SB, Kim-Sing C, et al. Waist-to-hip ratio and breast cancer mortality. Am J Epidemiol 2003;158:963 - 8. 
35. Lukanova A, Toniolo P, Akhmedkhanov A, et al. A cross-sectional study of IGF-I determinants in women. Eur J Cancer Prev 2001;10:443 - 52.

Table 1. Characteristics of sample by case/control status

\begin{tabular}{|c|c|c|c|}
\hline & $\begin{array}{c}\text { Cases } \\
(N=1,459)\end{array}$ & $\begin{array}{l}\text { Controls } \\
(N=1,556)\end{array}$ & $P$ \\
\hline Age [mean \pm SD $(y)]$ & $47.9 \pm 8.0$ & $47.2 \pm 8.8$ & 0.03 \\
\hline Education level (\%) & & & 0.04 \\
\hline No formal education & 4 & 5 & \\
\hline Elementary school & 9 & 8 & \\
\hline Middle and high school & 83 & 83 & \\
\hline College and higher & 5 & 4 & \\
\hline $\begin{array}{l}\text { Family history of breast } \\
\text { cancer }(\%)\end{array}$ & 4 & 2 & 0.05 \\
\hline Age at menarche $(y)$ & $14.5 \pm 1.6$ & $14.7 \pm 1.7$ & $<0.01$ \\
\hline Nulliparous (\%) & 5 & 4 & 0.12 \\
\hline Age at first live birth (\%) & & & $<0.01$ \\
\hline$<20$ & 5 & 5 & \\
\hline $20-24$ & 22 & 24 & \\
\hline $25-29$ & 51 & 55 & \\
\hline $30-34$ & 18 & 14 & \\
\hline$\geq 35$ & 4 & 3 & \\
\hline Menopausal status (\%) & 65 & 64 & 0.35 \\
\hline $\begin{array}{l}\text { Personal history of } \\
\text { fibroadenoma (\%) }\end{array}$ & 10 & 5 & $<0.001$ \\
\hline WHR & $0.81 \pm 0.06$ & $0.80 \pm 0.06$ & $<0.01$ \\
\hline BMI $\left(\mathrm{kg} / \mathrm{m}^{2}\right)$ & $23.5 \pm 3.5$ & $23.0 \pm 2.5$ & $<0.01$ \\
\hline $\begin{array}{l}\text { Physical activity } \\
\text { within last } 10 \text { y (\%) }\end{array}$ & 19 & 25 & $<0.01$ \\
\hline $\begin{array}{l}\text { Total energy intake } \\
{[\text { mean } \pm \text { SD }(\mathrm{kcal})]}\end{array}$ & $1,847 \pm 482$ & $1,822 \pm 481$ & 0.13 \\
\hline $\begin{array}{l}\text { Total fat intake } \\
{[\text { mean } \pm \text { SD }(g / d)]}\end{array}$ & $36.4 \pm 17.4$ & $35.3 \pm 16.2$ & 0.08 \\
\hline $\begin{array}{l}\text { Saturated fat intake } \\
{[\text { mean } \pm \mathrm{SD}(\mathrm{g} / \mathrm{d})]}\end{array}$ & $11.2 \pm 5.8$ & $10.7 \pm 5.1$ & 0.02 \\
\hline $\begin{array}{c}\text { Total fiber intake } \\
{[\text { mean } \pm \text { SD }(g / d)]}\end{array}$ & $10.1 \pm 4.3$ & $10.2 \pm 4.9$ & 0.33 \\
\hline $\begin{array}{c}\text { Red meat intake } \\
{[\text { mean } \pm \mathrm{SD}(\mathrm{g} / \mathrm{d})]}\end{array}$ & $43.9 \pm 32.2$ & $38.8 \pm 26.7$ & $<0.001$ \\
\hline $\begin{array}{l}\text { Vegetable intake } \\
{[\text { mean } \pm \text { SD }(g / d)]}\end{array}$ & $173.4 \pm 108.3$ & $171.7 \pm 110.6$ & 0.57 \\
\hline $\begin{array}{l}\text { Fowl intake } \\
{[\text { mean } \pm \text { SD }(g / d)]}\end{array}$ & $15.8 \pm 20.5$ & $13.9 \pm 15.8$ & $<0.01$ \\
\hline $\begin{array}{l}\text { Fish intake } \\
{[\text { mean } \pm \mathrm{SD}(\mathrm{g} / \mathrm{d})]}\end{array}$ & $37.5 \pm 39.8$ & $32.1 \pm 31.7$ & $<0.001$ \\
\hline $\begin{array}{l}\text { Legume intake } \\
\text { [mean } \pm S D(g / d)]\end{array}$ & $68.2 \pm 48.7$ & $70.3 \pm 58.1$ & 0.57 \\
\hline $\begin{array}{l}\text { Fruit intake } \\
\qquad[\text { mean } \pm \mathrm{SD}(\mathrm{g} / \mathrm{d})]\end{array}$ & $214.5 \pm 161.6$ & $211.3 \pm 161.2$ & 0.59 \\
\hline
\end{tabular}


Table 2. Factor loadings for foods associated with each dietary pattern in split samples of 1,556 controls in the Shanghai Breast Cancer Case-Control Study

\begin{tabular}{|c|c|c|c|c|c|}
\hline \multicolumn{3}{|c|}{ Vegetable-soy } & \multicolumn{3}{|c|}{ Meat-sweet } \\
\hline & Sample $1^{*}$ & Sample $2^{\dagger}$ & & Sample 1 & Sample 2 \\
\hline Fried tofu & 64 & 27 & Shrimp, crab & 35 & 34 \\
\hline Cauliflower & 60 & 34 & Candy, preserved fruit & 35 & 44 \\
\hline Lotus root & 60 & 28 & Chicken & 34 & 54 \\
\hline Freshwater fish & 59 & 25 & Desserts & 33 & 33 \\
\hline Tofu & 54 & 33 & Fresh milk & 30 & 33 \\
\hline Celery & 51 & 35 & Beef, lamb & 30 & 32 \\
\hline Fresh soybeans & 44 & 47 & Saltwater fish & 30 & 31 \\
\hline White turnips & 43 & 39 & Bread & 27 & 38 \\
\hline Tomato & 42 & 49 & Eel & 26 & 35 \\
\hline Cucumber & 41 & 48 & Conch & 25 & 15 \\
\hline Other fresh beans & 37 & 42 & Pork chops & 23 & 29 \\
\hline Chinese cabbage & 36 & 39 & Pig feet & 22 & 27 \\
\hline Wax gourd & 36 & 44 & Pork ribs & 21 & 27 \\
\hline Carrots & 34 & 41 & Organ meats & 20 & 48 \\
\hline Wild rice stem & 34 & 40 & Lean pork & 19 & 32 \\
\hline Mung bean sprouts & 33 & 29 & Liver & 19 & 48 \\
\hline Greens & 32 & 35 & Duck, goose & 17 & 27 \\
\hline Soy bean sprouts & 31 & 29 & & & \\
\hline Bamboo shoots & 28 & 27 & & & \\
\hline Soy milk & 27 & 20 & & & \\
\hline Asparagus & 22 & 37 & & & \\
\hline Green cabbage & 21 & 34 & & & \\
\hline$\%$ variance & 5.2 & 5.5 & & 4.6 & 3.1 \\
\hline Coefficient $\alpha$ & 0.78 & 0.75 & & 0.60 & 0.60 \\
\hline
\end{tabular}

${ }^{*} N=768$ women.

$\dagger N=788$ women. 
Table 3. Sociodemographic, reproductive, and dietary correlates for first and fourth dietary pattern quartiles in 1,446 cases and 1,549 controls in the Shanghai Breast Cancer Case-Control Study

\begin{tabular}{|c|c|c|c|c|}
\hline & \multicolumn{2}{|c|}{ Vegetable-soy pattern quartiles } & \multicolumn{2}{|c|}{ Meat-sweet pattern quartiles } \\
\hline & 1 & 4 & 1 & 4 \\
\hline Age [mean (SD), y] & $48(8)$ & $49(9)$ & $50(9)$ & $46(8)$ \\
\hline $\begin{array}{l}\text { Education level (\%) } \\
\text { No formal education }\end{array}$ & \multicolumn{4}{|c|}{ Education level (\%) } \\
\hline & 6 & 5 & 11 & 2 \\
\hline Elementary school & 9 & 8 & 14 & 4 \\
\hline Middle/high school & 75 & 72 & 69 & 78 \\
\hline College and higher & 10 & 16 & 6 & 16 \\
\hline BMI [mean (SD), $\left.\mathrm{kg} / \mathrm{m}^{2}\right]$ & $23.1(3.4)$ & $23.7(3.4)$ & $23.8(3.7)$ & $23.1(3.1)$ \\
\hline WHR [mean (SD́)] & $0.80(0.06)$ & $0.81(0.06)$ & $0.81(0.06)$ & $0.80(0.06)$ \\
\hline Physically active (\%) & 17 & 31 & 20 & 24 \\
\hline History of fibroadenoma (\%) & 5 & 9 & 3 & 3 \\
\hline Family history of breast cancer (\%) & 17 & 31 & 20 & 24 \\
\hline Age at menarche [mean (SD), y] & $14.5(1.7)$ & $14.6(1.7)$ & $14.9(1.7)$ & $14.4(1.6)$ \\
\hline \multicolumn{5}{|l|}{ Parity (\%) } \\
\hline Nulliparous & 5 & 5 & 5 & 5 \\
\hline \multicolumn{5}{|l|}{ Parous } \\
\hline \multicolumn{5}{|l|}{ Age at first live birth } \\
\hline$<20 y$ & 4 & 5 & 8 & 2 \\
\hline $20-24$ y & 24 & 23 & 26 & 19 \\
\hline $25-29 y$ & 51 & 49 & 44 & 53 \\
\hline $30-34 \mathrm{y}$ & 14 & 14 & 13 & 17 \\
\hline$\geq 35 \mathrm{y}$ & 3 & 4 & 4 & 4 \\
\hline \multicolumn{5}{|c|}{ Menopausal status/age at menopause (\%) } \\
\hline Premenopausal & 64 & 60 & 56 & 72 \\
\hline$\geq 55 \mathrm{y}$ & 2 & 2 & 2 & 1 \\
\hline $50-54$ y & 12 & 13 & 15 & 10 \\
\hline $45-49 y$ & 15 & 16 & 20 & 10 \\
\hline$<45 y$ & 7 & 8 & 8 & 6 \\
\hline \multirow{2}{*}{\multicolumn{5}{|c|}{$\begin{array}{l}\text { Intakes of foods and nutrients } \\
\text { per day (mean }+ \text { SD) }\end{array}$}} \\
\hline & & & & \\
\hline Red meat $(\mathrm{g})$ & $34.6 \pm 23.0$ & $48.2 \pm 34.1$ & $22.0 \pm 12.6$ & $63.3 \pm 36.4$ \\
\hline Fowl (g) & $10.6 \pm 12.4$ & $19.2 \pm 21.9$ & $5.2 \pm 5.4$ & $28.0 \pm 25.4$ \\
\hline Fish (g) & $21.1 \pm 21.7$ & $48.2 \pm 46.3$ & $20.1 \pm 20.6$ & $52.9 \pm 47.5$ \\
\hline Legumes (g) & $33.3 \pm 18.4$ & $116.7 \pm 71.3$ & $55.9 \pm 40.7$ & $83.8 \pm 54.2$ \\
\hline Vegetables (g) & $85.6 \pm 37.9$ & $293.0 \pm 119.7$ & $151.7 \pm 99.5$ & $204.7 \pm 118.6$ \\
\hline Fruits (g) & $159.8 \pm 123.4$ & $292.2 \pm 215.5$ & $159.2 \pm 127.8$ & $275.2 \pm 194.5$ \\
\hline Energy (kcal) & $1,631 \pm 382$ & $2,145 \pm 515$ & $1,588 \pm 359$ & $2,187 \pm 496$ \\
\hline Total fat $(\mathrm{g})$ & $27.6 \pm 12.6$ & $45.5 \pm 20.3$ & $22.8 \pm 10.3$ & $50.6 \pm 17.8$ \\
\hline Saturated fat (g) & $8.8 \pm 4.6$ & $13.4 \pm 6.6$ & $6.7 \pm 3.3$ & $15.6 \pm 65.9$ \\
\hline Soy protein $(\mathrm{g})$ & $5.6 \pm 4.0$ & $17.2 \pm 14.6$ & $9.2 \pm 7.4$ & $12.4 \pm 9.8$ \\
\hline Fiber (g) & $7.0 \pm 2.2$ & $14.6 \pm 5.4$ & $8.4 \pm 2.3$ & $12.3 \pm 4.9$ \\
\hline Vitamin A (IU) & $173 \pm 171$ & $271 \pm 357$ & $99 \pm 75$ & $392 \pm 427$ \\
\hline Vitamin C (mg) & $46 \pm 19$ & $135 \pm 52$ & $69 \pm 46$ & $101 \pm 52$ \\
\hline Calcium (mg) & $343 \pm 166$ & $689 \pm 273$ & $365 \pm 165$ & $633 \pm 249$ \\
\hline
\end{tabular}


Table 4. Adjusted OR estimates and $95 \%$ Cls by dietary pattern intake for 1,446 cases and 1,549 controls in the Shanghai Breast Cancer Case-Control Study

\begin{tabular}{|c|c|c|c|}
\hline \multirow[t]{2}{*}{ Dietary pattern } & \multirow[t]{2}{*}{ Cases/controls } & \multirow{2}{*}{$\frac{\text { Minimal model }}{\text { OR }(95 \% \text { CI })}$} & \multirow{2}{*}{$\frac{\text { Full model }^{\dagger}}{\text { OR }(95 \% \text { CI })}$} \\
\hline & & & \\
\hline $\begin{array}{l}\text { Vegetable-soy } \\
\text { Quartile } 1 \\
\text { Quartile 2 } \\
\text { Quartile } 3 \\
\text { Quartile 4 } \\
P_{\text {trend }} \\
\text { Meat-sweet }\end{array}$ & $\begin{array}{l}345 / 389 \\
376 / 389 \\
374 / 389 \\
364 / 389\end{array}$ & $\begin{array}{c}1.0 \\
1.1(0.9-1.3) \\
1.1(0.9-1.3) \\
1.0(0.8-1.2) \\
0.70\end{array}$ & $\begin{array}{c}1.0 \\
1.0(0.8-1.3) \\
1.0(0.8-1.3) \\
1.0(0.8-1.2) \\
0.61\end{array}$ \\
\hline $\begin{array}{l}\text { Quartile 1 } \\
\text { Quartile 2 } \\
\text { Quartile 3 } \\
\text { Quartile 4 } \\
P_{\text {trend }}\end{array}$ & $\begin{array}{l}311 / 380 \\
365 / 389 \\
372 / 389 \\
411 / 389\end{array}$ & $\begin{array}{c}1.0 \\
1.2(1.0-1.5) \\
1.2(1.0-1.5) \\
1.4(1.1-1.8) \\
0.01\end{array}$ & $\begin{array}{c}1.0 \\
1.1(0.9-1.4) \\
1.2(1.0-1.5) \\
1.3(1.0-1.7) \\
0.03\end{array}$ \\
\hline
\end{tabular}

"Models adjusted for age (continuous) and total energy (continuous).

†Models adjusted for above variables, and family history of breast cancer (yes, no), personal history of fibroadenoma (yes, no), age at menarche $(\leq 12,13,14,15$, $16, \geq 17 y)$, live births and age at first live birth $(<20,20-24,25-29,30-34, \geq 35$, nulliparous), menopausal status and age at menopause (premenopausal, age at menopause $<45,45-49,50-54, \geq 55 \mathrm{y}$ ), regular physical activity during last $10 \mathrm{y}$ (yes, no), waist-hip ratio (WHR, continuous), BMI (continuous), and level of education (no formal education, elementary, middle and high school, college and higher).

Table 5. OR estimates and $95 \%$ Cls for meat-sweet quartiles by menopausal status and estrogen receptor status

\begin{tabular}{|c|c|c|c|c|}
\hline & \multicolumn{2}{|c|}{ Premenopausal $(N=1,942)$} & \multicolumn{2}{|c|}{ Postmenopausal $(N=1,073)$} \\
\hline & Cases/controls & $\mathrm{OR}^{*}(95 \% \mathrm{CI})$ & Cases/controls & $\mathrm{OR}^{*}(95 \% \mathrm{CI})$ \\
\hline \multicolumn{5}{|l|}{ All cases } \\
\hline Quartile 1 & $185 / 203$ & 1.0 & $126 / 186$ & 1.0 \\
\hline Quartile 2 & $226 / 242$ & $1.1(0.8-1.4)$ & $139 / 147$ & $1.2(0.9-1.8)$ \\
\hline Quartile 3 & $249 / 261$ & $1.1(0.8-1.4)$ & $123 / 128$ & $1.4(1.0-2.0)$ \\
\hline Quartile 4 & $292 / 284$ & $1.2(0.9-1.6)$ & $119 / 105$ & $1.6(1.0-2.4)$ \\
\hline \multirow{2}{*}{\multicolumn{5}{|c|}{ Estrogen receptor positive }} \\
\hline & & & & \\
\hline Quartile 1 & $70 / 203$ & 1.0 & $49 / 186$ & 1.0 \\
\hline Quartile 2 & $99 / 242$ & $1.2(0.8-1.8)$ & $56 / 147$ & $1.3(0.8-2.1)$ \\
\hline Quartile 3 & $112 / 261$ & $1.3(0.9-1.9)$ & $52 / 128$ & $1.6(0.9-2.6)$ \\
\hline Quartile 4 & $132 / 284$ & $1.4(0.9-2.1)$ & $52 / 105$ & $1.9(1.1-3.3)$ \\
\hline$P_{\text {trend }}{ }^{\dagger}$ & $1027<08$ & 0.11 & 027100 & 0.03 \\
\hline \multicolumn{5}{|c|}{ Estrogen receptor negative } \\
\hline Quartile 1 & $56 / 203$ & 1.0 & $27 / 186$ & 1.0 \\
\hline Quartile 2 & $55 / 242$ & $0.8(0.5-1.3)$ & $31 / 147$ & $1.2(0.6-2.2)$ \\
\hline Quartile 3 & $71 / 261$ & $1.1(0.7-1.6)$ & $23 / 128$ & $1.1(0.6-2.3)$ \\
\hline Quartile 4 & $65 / 284$ & $0.9(0.5-1.4)$ & $24 / 105$ & $1.5(0.7-3.3)$ \\
\hline$P_{\text {trend }}{ }^{\top}$ & & 0.80 & & 0.31 \\
\hline
\end{tabular}

"Models adjusted for age (continuous), total energy (continuous), family history of breast cancer (yes, no), personal history of fibroadenoma (yes, no), age at menarche $(\leq 12,13,14,15,16, \geq 17 y)$, live births and age at first live birth $(<20,20-24,25-29,30-34, \geq 35$, nulliparous), menopausal status and age at menopause (premenopausal, age at menopause $<45,45-49,50-54, \geq 55 \mathrm{y}$ ), regular physical activity during last $10 \mathrm{y}$ (yes, no), waist-hip ratio (WHR, continuous), BMI (continuous), and level of education (no formal education, elementary, middle and high school, college and higher).

t $P$ value for trend was obtained for each pattern by including in the model a variable representing the median value for each quartile. 
Table 6. OR estimates and $95 \% \mathrm{Cls}$ by meat-sweet pattern intake for estrogen receptor-positive breast cancers stratified by BMI and WHR among postmenopausal women

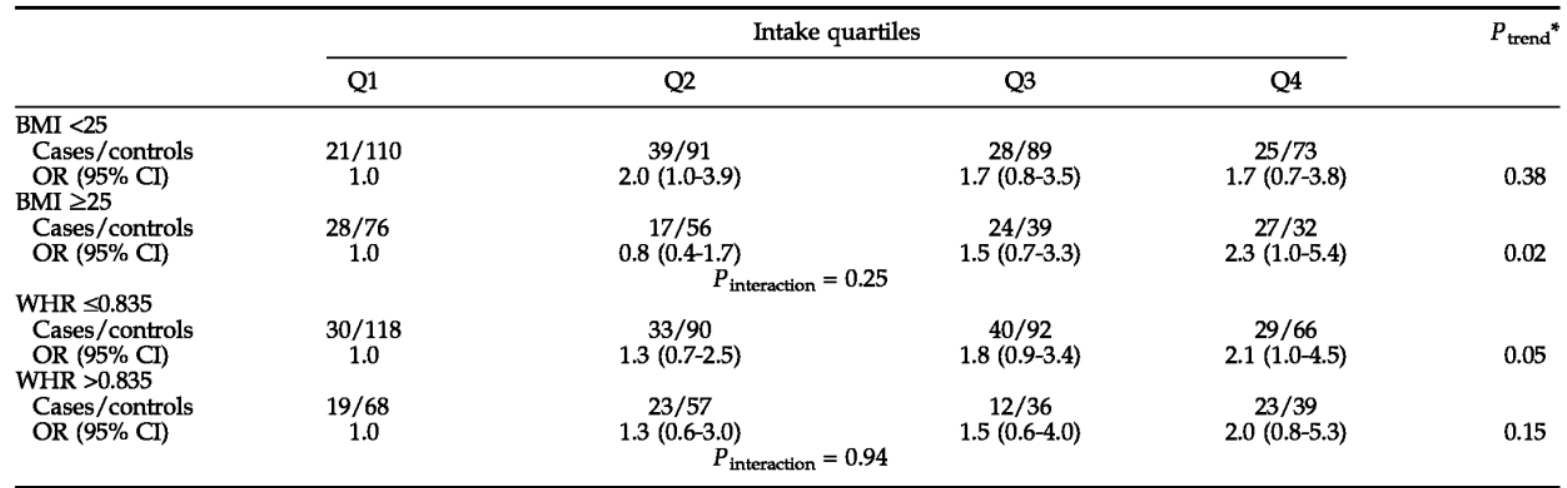

NOTE: Models were adjusted for age (continuous), total energy (continuous), family history of breast cancer (yes, no), personal history of fibroadenoma (yes, no), age at menarche $(\leq 12,13,14,15,16, \geq 17 y)$, live births and age at first live birth $(<20,20-24,25-29,30-34, \geq 35$, nulliparous), menopausal status and age at menopause (premenopausal, age at menopause $<45,45-49,50-54, \geq 55 \mathrm{y}$ ), regular physical activity during last $10 \mathrm{y}$ (yes, no), WHR (continuous), BMI (continuous), and level of education (no formal education, elementary, middle and high school, college and higher).

${ }^{*} P$ value for trend was obtained for each pattern by including in the model a variable representing the median value for each quartile. 